González Damián, A. (2017)

\title{
Construcción social de la experiencia turística. Una cooproducción de turistas y de anfitriones basada en hechos reales
}

España: Bubok publishing

Rodrigo Espinoza Sánchez y Rosa María Chávez Dagostino

Centro Universitario de la Costa

Universidad de Guadalajara

rodrigoe@cuc.udg.mx, rosac@cuc.udg.mx

E I autor del libro la Construcción social de la experiencia turística. Una coproducción de turistas y anfitriones basada en hechos reales es un excelente académico, compañero y amigo: Alfonso González Damián, cuya preocupación por los diferentes abordajes de los estudios turísticos lo han conducido a explorar diversidad de temas de este fenómeno, en el que engrana una complejidad sistémica que orienta el desarrollo estructural de esta obra, la cual parte de ciertos supuestos teórico-metodológicos y de hechos reales que ayudan a comprender la gestación y concreción de la experiencia turística.

En la introducción el autor señala que después de la Segunda Guerra Mundial, el turismo tomó un papel preponderante en el desarrollo económico de los países y, por ende, este fenómeno empezó a ser estudiado por los oferentes con el objeto de crear productos turísticos que satisficieran los requerimientos del turista y que su experiencia fuera exitosa. Luego argumenta González Damián que han proliferado estudios que se enfocan desde la perspectiva del turista en la obtención de la experiencia única, mientras que desde el ángulo de la anfitrionía no se ha abordado como debiera; por tanto, su consideración es que el estudio de esta experiencia turística se ha parcelado y se ha obviado la otredad que participa en la creación del producto para que la experiencia tenga lugar, ya que esta se da a través del construccionismo social. El contenido de la obra está fundamentado en casi dos centenares de referencias y se estructura en seis capítulos en los que se analizan otros abordajes al estudio de la experiencia turística.

El primer capítulo, "Realidad social, construccionismo y turismo", parte de un cuestionamiento central acerca del propio construccionismo, que en sí mismo encierra una gran discusión, la cual motiva el cuestionamiento acerca de si el construccionismo es una teoría, un paradigma o una moda. Para dar respuesta, el autor recurre a diversos estudios y ofrece elementos que permiten identificar y diferenciar aspectos teórico-conceptuales que están implícitos en la intersubjetividad e interpersonalidad de los hechos sociales que se 
estudian; sin embargo, llega a la conclusión de que existen diferencias desde su concepción epistémica, ya que este construccionismo aglutina teorías y métodos que coinciden en su fundamentación epistémica, lo que puede ser considerado desde dos posturas, según los teóricos, una fuerte y otra débil. En la primera: 1) el conocimiento no es un mundo que depende de un observador; 2) el conocimiento no representa tal mundo; 3) el conocimiento se refiere a la experiencia individual más que al mundo; 4) no hay una realidad extra-experiencia racionalmente. Por tanto, la verdad de ese conocimiento reside en lo que los seres humanos construyen. La segunda postura es opuesta, si bien el conocimiento del mundo natural es accesible para el ser humano, entonces existe como tal, mientras que el conocimiento de lo social es inaccesible, por tanto, debe ser construido. Ante estas posturas el autor argumenta que el construccionismo es aquel cuyas bases se gestan en lo colectivo y no en el individualismo ni el realismo o el racionalismo, ya que estas posturas son inadecuadas para su aprehensión. Por tanto, el conocimiento turístico es producto de un proceso dialéctico en el cual se fusiona el elemento objetivo, constituido por las relaciones sociales de los sujetos, y uno subjetivo, que es la interpretación de los símbolos, internalización de los roles y la formación de identidades individuales. En este sentido, se apela a la reflexión para la generación del conocimiento, desde la postura construccionista con sustento epistemológico.

En el segundo capítulo, "La experiencia turística en la literatura académica”, se analiza la complejidad de entender la experiencia turística y se "da un paseo" que muestra cómo se ha manejado la integración de productos turísticos según los recursos que posee el territorio en el cual se suscita la experiencia, pero a la vez, hace reflexionar ante tal perspectiva, ya que en ocasiones, la experiencia turística auténtica no se genera por los recursos considerados como atractivos, sino por lo que el turista va a realizar y no sólo a ver. Muestra así la evolución del manejo del mercado turístico desde la oferta, cada día más especializada, para dar respuesta a una demanda muy selectiva. Hace referencia también, a que en ese devenir evolutivo el turista concentra su atención en una inmersión, ya no solo de lo que va a hacer, sino que ahora quiere sentir además de ver y hacer; es decir, dónde experimentar vivencias, por lo que la industria tiene que redoblar esfuerzos y ofrecerlas. En este capítulo, se abordan los modos de la experiencia turística y como se representan. Cierra con una reflexión acerca de lo que el autor denomina paisaje turístico y cosificación de la comunidad anfitriona, e invita a una nueva concepción de experiencia turística desde una perspectiva más interpersonal y humana.

En el tercer capítulo, "Hacia una teoría construccionista de la experiencia turística", se identifican los esfuerzos que se han hecho desde el siglo pasado por entender desde otra óptica la experiencia turística, que era vista desde la perspectiva de la economía; sin embargo, el autor cuestiona cómo se puede diferenciar la experiencia de un viaje turístico de un viaje cualquiera. Considera que la industria solo hace la distinción de turista para fines mercadológicos y el gobierno para fines estadísticos. Esto trae ciertas confusiones, ya que si solo se considera al turista se está dejando de lado al que hace posible dicha experiencia como resultado de la acción del colectivo denominado anfitriones. Para complejizar este construccionismo de la 
experiencia turística se hace referencia a marcos en los cuales se da la experiencia, pero a la vez se determina y explican ciertas dimensiones que competen al binomio turista y anfitrión, como construcción colectiva.

El cuarto capítulo, “Construcción colectiva de la experiencia turística”, presenta un estudio de caso de Cozumel, y enfatiza los soportes teórico referenciales importantes para indicar el significado que tienen los marcos en la construcción colectiva de la experiencia turística. El autor trata de contrastar la teoría y la práctica con experiencias turísticas en el contexto de la isla de Cozumel, pero a la vez plantea una metodología basada en los cuatro marcos primarios de todo viaje turístico: a) Planeación del viaje, b) Planeación hacia y desde el destino, c) Estancia en el destino y d) Experiencia posviaje; donde el trabajo empírico pueda abarcar a toda la experiencia a través de la observación participante y no participante, y establece que la concreción de la experiencia turística, a pesar de estar concebida dentro de marcos tipificados de la industria del turismo, depende de una interpretación de la anfitrionía.

El quinto capítulo, "Transformación de las experiencias del viajero como turista ante la presencia de tecnología”, vuelve a retomar la experiencia del turista como un constructo colectivo, esto lo enfatiza al decir que dicha experiencia se construye porque es un hecho social en el que interviene tanto el turista como la comunidad anfitriona. A la vez, hace una aproximación empírica a la experiencia turística en los recorridos subacuáticos de la isla en Cozumel, México, a través de los marcos de la experiencia turística en los referidos recorridos, en tanto plantea un modelo conceptual de la intervención de la tecnología en estos marcos de la experiencia turística, que se sustenta en dos vertientes: 1) una relacionada al uso intensivo de la tecnología para beneficio del desarrollo del turismo, y 2) los efectos de los desarrollos tecnológicos en el turismo, sin embargo, señala que el sector turismo no ha quedado rezagado del uso de las tecnologías. El capítulo cierra con reflexiones sobre nuevas líneas de investigación que posibiliten aproximaciones cualitativas construccionistas para entender lo que sucede con las interacciones entre anfitriones y turista cuando interviene la tecnología.

El sexto y último capítulo, "Límites y posibilidades del concepto de experiencia turística colectivamente construido", enfatiza que el construccionismo colectivo puede sentar bases sólidas para el estudio del turismo y específicamente de la experiencia turística, toda vez que este se sustenta en las relaciones interpersonales que se dan entre turista y comunidad anfitriona. Refiere que en los capítulos precedentes de la obra están los planteamientos teóricos para su aplicación, y en este capítulo se encuentran algunas limitantes de la experiencia turística socialmente construida. Finalmente, los hallazgos presentados en el libro y las líneas de investigación que deja el autor, plasmadas como inquietudes para proseguir la investigación, son un reto para la indagación y profundización de su interpretación desde los variados enfoques teóricos y metodológicos. 